\title{
A physiological study of the anorectal reflex in patients with functional anorectal and defecation disorders
}

\author{
Kumaran THIRUPPATHY ${ }^{1,2}$, John MASON ${ }^{1}$, Khalid AKBARI ${ }^{1}$, Amanda \\ Raeburn $^{2}$, Anton EMMANUEL ${ }^{2}$
}

${ }^{1}$ Department of Colorectal Surgery, Royal Berkshire Hospital, Craven Road, Reading, RG1 5AN, UK

\author{
${ }^{2}$ Physiology Unit, University College Hospital, 235 Euston Road, London, \\ NW1 2BU, UK
}

Author for correspondence: Mr K Thiruppathy

Address: Department of Colorectal Surgery, Royal Berkshire Hospital, Craven Road, Reading, RG1 5AN, UK

Telephone: +44 1183225111

Email: kum.nhs@gmail.com

Sources of funding: nil to declare

Conflicts of interest: nil to declare

\begin{abstract}
OBJECTIVE: The symptoms of fecal incontinence and constipation can arise from a variety of alterations of anorectal function. The aim of this study was to investigate components of the anorecal reflex in patients with these
\end{abstract}

This article has been accepted for publication and undergone full peer review but has not been through the copyediting, typesetting, pagination and proofreading process, which may lead to differences between this version and the Version of Record. Please cite this article as doi: $10.1111 /$ cdd.12462

This article is protected by copyright. All rights reserved. 
symptoms, to determine the functional significance of the various physiological parameters.

METHODS: 21 healthy volunteers (controls), 78 incontinent and 74 constipated patients were recruited and symptom burden determined using the Wexner incontinence and constipation questionnaires. All participants underwent standardised anorectal physiology including anorectal manometry, anorectal distension and electrosensitivity thresholds, rectal mucosal blood flow and rectoanal inhibitory reflex measurement.

RESULTS: Patients with passive incontinence had lower resting sphincter pressures than controls ( 38 vs $87 \mathrm{cmH}_{2} \mathrm{O}, \mathrm{p}<0.05$ ), while those with urge incontinence had lower squeeze pressures than controls (37 vs $119 \mathrm{cmH}_{2} \mathrm{O}$, $p<0.05)$. Patients with urge incontinence had lower maximal tolerable volumes (100 vs $166 \mathrm{~mL}, \mathrm{p}<0.05)$. Patients with slow transit constipation had elevated rectal electrosensitivity thresholds compared to controls (31.4 vs 20.2 , $\mathrm{p}<0.05)$, and also showed lower mucosal blood flow than patients with evacuation difficult and controls (107 vs 162 (evacuation difficult) vs 169 (controls), $p<0.05)$. Only patients with passive incontinence were associated with reflex abnormalities (prolonged recovery phase $(1.2$ vs $0.5 \mathrm{msec}, p<0.05)$ and total duration of reflex (6.3 vs $4.3 \mathrm{msec}, \mathrm{p}<0.05))$.

CONCLUSION: Anorectal motor, sensory and reflex abnormalities are seen in distinct patterns in patients with fecal incontinence and constipation. This would suggest distinct physiological differences which may predict the

This article is protected by copyright. All rights reserved. 
potential for different treatment neuromodulation and behavioural modalities in these conditions.

Keywords: anorectal physiology, rectoanal inhibitory reflex, fecal incontinence, constipation

This article is protected by copyright. All rights reserved. 


\section{Introduction}

Idiopathic fecal incontinence $(\mathrm{FI})$ is a functional anorectal disorder that affects up to $8 \%$ of individuals, ${ }^{1}$ whilst functional defecation disorders affect up to $19 \%$ of the North American population. ${ }^{2}$ Both have a higher prevalence amongst females and the elderly. ${ }^{34}$ The significant negative impact between symptom burden and impaired quality of life is well established in patients suffering from $\mathrm{Fl}$ or constipation. ${ }^{5}$

Anorectal physiology forms an important component of FI assessment, although its value remains controversial. Currently the most common recorded variables are: static and squeeze anal sphincter pressures, sensitivity to rectal distention and mucosal electro-stimulation. ${ }^{6}$ Studies of anal sphincter function do not reliably correlate with symptoms, as for example, not all patients with low sphincter pressures suffer from $\mathrm{FI}^{78}$ Moreover, a sub-set of patients with FI and proven low anal sphincter pressures report an improvement in symptoms with sacral nerve stimulation, which does not alter anal sphincter function. ${ }^{9}$ This has led to the theory that the etiology of functional $\mathrm{FI}$ involves not just anal sphincter function, but also rectal function.

Extrinsic neural control of rectal and anal sphincter through the pudendal and autonomic nerves (ANS) is central to controlling continence. Pudendal nerve function can be measured by Pudendal Nerve Terminal Motor Latency (PNTML), however the results do not consistently correlate with anorectal function, symptoms or treatment outcomes. ${ }^{10}{ }^{11}$ ANS function may be 
assessed using rectal mucosal blood flow (RMBF) as a surrogate marker of gut specific function, and has been shown to correlate with severity of constipation in patients with multiple sclerosis (MS) and spinal cord injury. ${ }^{12}$

The rectoanal inhibitory reflex (RAIR) is an intrinsic reflex influenced by descending spinal pathways. This dynamic reflex is characterised by relaxation and then a contraction of the anal sphincters in response to rectal distension, and is a major contributor to continence. ${ }^{13}$ Abnormalities of the RAIR have been implicated in both constipation and FI in patients with diabetes, scleroderma, multiple sclerosis and spinal cord injury. ${ }^{121415}$

The relationship between altered anorectal physiology and functional FI and constipation is poorly understood. The study of static and dynamic anorectal physiology may provide an important tool for understanding the pathology of functional anorectal disease and may reveal potential treatment options. Therefore, the aim of this study was to investigate the relationship between anorectal physiological parameters (including: PNTML, manometry, mucosal electro-stimulation, RAIR and RMBF) in patients with symptoms of functional anorectal and defecation disorders.

\section{Methods}

This single centre prospective case-control study was undertaken at the Physiology Unit at University College Hospital, London, UK. Full ethical approval was granted by St Mark's \& Northwick Park Ethics Committee.

This article is protected by copyright. All rights reserved. 


\section{Patients \& controls}

Adult patients referred to the Physiology Unit at University College Hospital were recruited. Patients under 18 years old, a previous history of colorectal or anal surgery (including surgical or orifice treatment for haemorrhoids), symptoms suggestive of irritable bowel syndrome (as defined by the Rome III criteria) or any other systemic disease affecting gastrointestinal function (including: diabetes, multiple sclerosis, spinal cord injury and connective tissue disorders were excluded.

All patients underwent a full clinical assessment including a detailed history of symptom burden. Patients with a medication history that may influence bowel function were excluded. Organic disease was further excluded through comprehensive laboratory tests and lower gastrointestinal endoscopy. The Rome III criteria was applied to differentiate functional anorectal disorders (namely FI predominant symptoms) from functional defecation disorders. This enabled classification into one of four groups: 1) urge $\mathrm{FI}, 2$ ) passive $\mathrm{FI}, 3$ ) slow transit and 4) evacuation difficulty. Following group allocation, symptom load was then assessed using the validated Wexner questionnaires for constipation $^{16}$ and $\mathrm{FI}^{17}$

Healthy volunteers (controls) were recruited by hospital advertisements and no financial incentives were offered. The same exclusion criteria used for recruitment of patients from the physiology unit were also applied to healthy controls.

This article is protected by copyright. All rights reserved. 
All patients and controls underwent a series of standardised physiological investigations including: anal manometry, evaluation of rectal sensory thresholds, evaluation of pudendal nerve function and rectal mucosal blood flow.

\section{Anorectal physiological investigations}

Whole gut transit study

Patients allocated to the constipation predominant groups underwent whole gut transit time assessment through ingestion of radio opaque markers (Dunn Clinical Nutrition, Cambridge, UK) over a three day period and timed plain abdominal films using the validated method described by Evans et al (1992). ${ }^{18}$ Healthy volunteers should retain approximately $20 \%$ of markers within 12 hours and less than $80 \%$ after 120 hours. This enabled classification of patients into two groups: slow transit constipation or rectal evacuation disorder with normal transit time.

\section{Anorectal manometry}

Anorectal manometry was performed using an eight-channel water perfused catheter linked to a pneumohydraulic water perfusion system (Medial Measurements Systems, Enschede, Netherlands). Functional anal canal length and maximum voluntary and involuntary squeeze pressures were determined using a stationary pull through method. ${ }^{10}$

Rectal distension sensitivity thresholds

This article is protected by copyright. All rights reserved. 
Rectal sensation was assessed by slow inflation of a latex rectal balloon (Ardmore Healthcare, Bognor Regis, UK) with air at $1 \mathrm{~mL} / \mathrm{s}$ to elicit the following variables: threshold volume for first constant sensation, defecatory urge volume (DDV), and maximum tolerable volume (MTV). Based on previous studies in this unit, normal ranges were set as: threshold volume of $20-110 \mathrm{~mL}$, DDV of $60-170 \mathrm{~mL}$ and MTV of $110-320 \mathrm{~mL} .^{12}$

\section{Pudendal nerve terminal motor latency}

Pudendal nerve terminal motor latency (PNTML) was assessed with the St Mark's Pudendal Stimulating Electrode (Dantec Medical, Skovlunde, Denmark). Age adjusted PNTML values were used in order to assess for the presence of pudendal neuropathy (PNTML $>2.3 \mathrm{~ms}$ below 40 -years-old, and $>2.5 \mathrm{~ms}$ in those 40 -years or older. ${ }^{19}$ )

\section{Anorectal electrosensitivity thresholds}

A biopolar electrode ring catheter (Gaeltec Devices Ltd, Strathclyde, UK) and the Dantec Keypoint EMG/NCS/EP Workstation (Natus Medical Incorporated, Pleasanton, CA, USA) was used to assess anal and rectal mucosal electrosensitivity thresholds. Briefly, the protocol involved initial electrical stimulation of the anal canal at $5 \mathrm{~Hz}$ with a pulse width of $0.1 \mathrm{~ms}$, followed by an incremental increase in the current to a maximum of $20 \mathrm{~mA}$ or until the patient reported a change in sensation. Values for the rectum were an initial stimulation of $10 \mathrm{~Hz}$, pulse width $0.5 \mathrm{~ms}$ and increased to a maximum of $50 \mathrm{~mA} .^{20}$

This article is protected by copyright. All rights reserved. 
Rectoanal inhibitory reflex

The rectoanal inhibitory reflex (RAIR) was assessed by insertion of a latex rectal balloon (Ardmore Healthcare, Bognor Regis, UK) into the lower rectum and rapid inflation and deflation with $50 \mathrm{~mL}$ of sterile water. Changes in pressure were recorded using the eight-channel manometry catheter. Persistent failure to elicit the RAIR despite repositioning the catheter prompted an increase in the inflation volume to $100 \mathrm{~mL}$. The following parameters were measured: excitation latency, the percentage reduction in amplitude of the anal pressure compared to resting anal pressure, recovery time and total duration of the reflex (further details provided in figure 1). If the RAIR was observed in multiple catheter channels the one demonstrating the largest change in amplitude was selected for analysis.

\section{Rectal mucosal blood flow}

Rectal mucosal blood flow (RMBF) was assessed using a Doppler probe (DP6A Moor Instruments, Axminster, UK) at $10 \mathrm{~cm}$ from the anal verge at four circumferential points after allowing stabilisation of the trace for at least 30 seconds.

\section{Statistical analysis}

Five study groups were defined based on clinical and physiological assessment: 1) controls, 2) urge $\mathrm{FI}, 3$ ) passive $\mathrm{FI}, 4$ ) slow transit and 5) evacuation difficult constipation. All controls were matched for age and sex. Normally distributed variables were expressed as mean (+/- SD) otherwise they were recorded as median and ranges. Comparisons between control and 
patient groups were performed using one-way analysis unpaired t-test for parametric data, or Mann-Witney U test for non-parametric data. SPSS 20 (IBM, Armonk, New York, USA) was used for all statistical tests.

\section{Results}

Twenty one healthy volunteers (controls, 14 female; mean age 35) and 152 patients (age range 18-72) were included. Seventy eight patients (63 female; mean age 45) had FI-predominant symptoms (44 urge $\mathrm{FI}$ and 34 passive $\mathrm{FI}$ ), and 74 patients (59 female; mean age 32 ) had constipation-predominant symptoms ( 47 slow transit, defined by whole gut transit studies and 27 with evacuation difficulty.

\section{Questionnaires}

Mean (SD) scores for Wexner FI and constipation scores are shown in table 1. The symptom questionnaires demonstrated that controls had low symptom scores, consistent with previous studies. Patients with urge or passive FI had significantly higher Wexner FI scores than controls $(p<0.001)$. Similarly, patients with slow transit $(p<0.03)$ or evacuation difficulty $(p<0.01)$ had higher Wexner constipation scores than controls

\section{Anorectal physiology \\ Anal manometry}

Mean (SD) resting and squeeze sphincter pressures are shown in table 2. Patients with FI-predominant symptoms had lower resting and squeeze pressures than controls $(p<0.05)$. Patients with passive $\mathrm{FI}$ had lower resting 
sphincter pressures than controls ( 38 vs $\left.87 \mathrm{cmH}_{2} \mathrm{O}, \mathrm{p}<0.05\right)$ and patients with urge $\mathrm{FI}\left(38\right.$ vs $\left.53 \mathrm{cmH}_{2} \mathrm{O}, \mathrm{p}<0.05\right)$. Patients with urge $\mathrm{FI}$ had lower squeeze pressures than controls (37 vs $\left.119 \mathrm{cmH}_{2} \mathrm{O}, \mathrm{p}<0.05\right)$ and patients with passive $\mathrm{FI}\left(37\right.$ vs $\left.84 \mathrm{cmH}_{2} \mathrm{O}, \mathrm{p}<0.05\right)$. Patients with constipation-predominant symptoms had no disturbance of anal sphincter pressures.

Rectal sensory function to distension (table 2)

Patients with urge FI required lower volumes to elicit first sensation, DDV and MTV as compared to all other groups. However, only the reduced MTV was statistically significant when compared to controls (100 Vs $166 \mathrm{~mL}, p<0.05)$. Patients with slow transit and evacuation difficulty-constipation reported elevated volumes to elicit these variables, although only DDV was statistically significant volume when compared to controls and both urge and passive FI (94 (slow transit), 90 (evacuation difficulty) vs $69 \mathrm{~mL}$ (controls), $p<0.05$ ).

Pudendal nerve terminal motor latency \& anorectal electrosensitivity thresholds (figure 2)

All controls and patients had age appropriate PNTMLs. All controls and patients with urge or passive FI and evacuation difficulty had normal anorectal electrosensitivity thresholds. Patients with slow transit constipation had elevated rectal electrosensitivity thresholds compared to controls (31.4 vs $20.2, p<0.05)$

Rectal mucosal blood flow

This article is protected by copyright. All rights reserved. 
RMBF in patients with incontinence-predominant symptoms were similar to those observed in controls. Patients with slow transit constipation had decreased RMBF when compared to both patients with evacuation difficult and controls (107 vs 162 (evacuation difficult), 169 (controls), $p<0.05$ ).

\section{Rectoanal inhibitory reflex (table 3)}

Urge FI was not associated with any significant abnormalities of the RAIR when compared to controls. In contrast, passive FI was associated with a prolonged recovery phase ( 1.2 vs $0.5 \mathrm{msec}, \mathrm{p}<0.05)$ and total duration of reflex $(6.3$ vs $4.3 \mathrm{msec}, \mathrm{p}<0.05)$ when compared to controls. Patients with constipation predominant symptoms were not associated with any abnormalities in the RAIR reflex parameters compared with controls or incontinence-predominant patients.

\section{Discussion}

This was a single centre study investigating the physiological parameters of the anorectal reflex in patients with functional anorectal and defecation disorders. This heterogeneous cohort of patients often have limited treatment options, which are compounded by unpredictable treatment outcomes. These challenges even more complex in the absence of known organic causes, meaning that patients with functional (idiopathic) anorectal and defecation disorders represent a particularly challenging cohort of patients to manage.

The relationship between anorectal physiology and functional FI and constipation has previously been investigated by Zbar et al (1998). ${ }^{21}$ 
However, their study failed to address the heterogeneity of symptoms within each patient group (i.e. urge FI vs passive $\mathrm{FI}$ and slow transit vs evacuation difficult constipation). This represents an important source of bias, making interpretation of results difficult and hinders application to real life clinical practice. In contrast, our study overcame this limitation by analysing patients according to the exact nature of their $\mathrm{Fl}$ and constipation in order to demonstrate physiological differences underpinning symptom burden. This may enable more effective targeting to treatment options.

Patients with functional (idiopathic) FI or constipation had relatively disparate symptom profiles. Unsurprisingly, those with FI had low constipation scores whilst those with predominant symptoms of constipation had low FI scores. Of note, this is in contrast to patients with central neuropathy syndromes who describe a mixed symptom burden. ${ }^{22}$ Abnormalities in rectal sensation are considered to be important in the development of anorectal dysfunction. ${ }^{23}$ In this study, rectal balloon distension demonstrated reduced rectal sensory thresholds in patients with urge FI, but not passive FI. Chan et al (2005) demonstrated similar findings in a subset of patient with urge $\mathrm{FI}$, suggesting that symptom burden within this cohort of patients is secondary to rectal hypersensitivity. ${ }^{24}$ Moreover, patients with urge $\mathrm{Fl}$ in this study also reported decreased voluntary anal squeeze pressures (external anal sphincter function) suggesting a pathophysiological association between rectal sensation and voluntary sphincter action within patient group. It is unclear if lower squeeze pressures leads to rectal conditioning to lower rectal volumes in an effort to avoid urge FI. Alternatively, rectal hypersensitivity may lead to 
impaired tolerance of rectal distention to relatively low rectal volumes and in turn to urge FI.

This study did not show any variation in PNTML and symptom burden across all patient groups. The relevance of this is unclear, and may reflect the findings of previous studies that suggest measurement of PNTML is an insensitive test for underlying neuropathy. ${ }^{25}$ For examples, Hill et al (2002) found that $31 \%$ of patients with bilaterally prolonged PNTML had normal squeeze pressures, and $49 \%$ with normal PNTML had abnormal squeeze pressures. ${ }^{8}$ It is possible that these results reflect the underlying limitations of this method of measuring extrinsic neuronal control, whereby the presence of a few nerve fibres (insufficient to provide reliable control of continence) result in false positives. Furthermore, the test is highly operator dependant and poorly tolerated by patients.

Patients with known functional (idiopathic) constipation have been shown to have diminished rectal sensation to distention, resulting in rectal mucosal sensation to electrical stimulation. ${ }^{26}$ This study revealed that this finding is unique to patients with slow transit, but not evacuation difficult constipation. In contrast to $\mathrm{Fl}$, this indicates an element of rectal hyposensitivity, and similar findings have been reported in patients with diabetes and MS. ${ }^{12} 14$ Sensation to electrical stimulation is detected by non-myelinated c-fibres within the rectal mucosa, and is transmitted to higher centres via parasympathetic fibres within the nervi erigentes. Abnormal myenteric plexus transmission and altered

This article is protected by copyright. All rights reserved. 
neurotransmitter concentrations have been observed in patients with slow transit constipation indicating visceral neuropathy etiology. ${ }^{27}$

Consistent with previous studies, ${ }^{28}$ we found that RMBF is reduced in patients constipation-predominant symptoms, although this study revealed that this finding is unique to patients with slow transit constipation only. RMBF is used as a surrogate measurement of colonic and rectal autonomic tone. Reduced RMBF is associated with psychological stress, ${ }^{29}$ muscarinic antagonists ${ }^{30}$ and constipation. Indeed, RMBF has previously been shown to correlate with severity of constipation. ${ }^{31}$ As functional (idiopathic) anorectal and defecation disorders are often multifactorial, these findings provide evidence that autonomic tone is affected in patients suffering from constipation-predominant symptoms.

Normal RAIR is mediated by both sacral and myenteric neurones, and abnormal RAIR morphology has previously been shown to correlate with $\mathrm{FI}^{32}$ Within this study, abnormal RAIR morphology was found only in patients with passive FI. Previous investigations of healthy volunteers have shown that resting pressures are largely governed by the internal anal sphincter, which relaxes in response to rectal distention, whilst the external anal sphincter contracts involuntarily (during the so-called rectal sampling reflex). ${ }^{33}$ Patients with passive incontinence had prolonged relaxation and recovery phases of the RAIR. The combination of lower resting pressures, any prolongation of the RAIR is likely to reduce sphincter pressures further, and therefore predispose 
to passive FI. Similar reflex patterns amongst patients with idiopathic passive incontinence have been demonstrated. ${ }^{21}$

This group has previously reported on disturbances in anorectal physiology in patients with neurogenic (MS and $\mathrm{SCl}$ ) and diabetic-associated bowel disorders ${ }^{12}{ }^{14}$. Severity of constipation in MS and SCl correlates with reduced RMBF, a finding that was mirrored for patients in this study with slow transit functional constipation. Severity of FI symptoms in patients with $\mathrm{MS}, \mathrm{SCl}$ and diabetes correlates with abnormalities of the RAIR, namely prolonged duration and recovery. In this study, similar findings were shown for patients with passive FI but not urge FI. While patients with neurogenic bowel disorders and constipation predominant symptoms are known to have impaired relaxation of the anal sphincters during the RAIR, patients with functional constipation consistently demonstrate an intact reflex. Further research should now be undertaken to evaluate the role of these investigations in the management of functional anorectal and defecation disorders. The observations reported in this study may be clinically useful in selecting appropriate treatment options for patients with functional anorectal and defecation disorders, whereby patients with preserved anorectal sensation may be suitable candidates for biofeedback, whereas trans-anal irrigation may be more appropriate in patients with intact anorectal reflexes.

It could be argued that the predominance of females included in the study may limit generalisability of our results. Alternatively, it may simply reflect the increased prevalence of $\mathrm{FI}$ and constipation among female patients. ${ }^{3}$ Indeed, 
FI has been shown to be up to eight times more prevalent in women, which is largely attributed to obstetric factors. ${ }^{34}$ Similarly, the prevalence of functional (idiopathic) constipation has been reported as affecting up to $15 \%$ of women compared to $5.2 \%$ of men. ${ }^{35}$ All of the physiological measurements were performed in all subjects (controls and patients). While the order of investigations was standardised, it is possible that this order influenced subsequent measurements.

In summary, the findings of this novel study provide new insights into the pathophysiology of the different symptom profiles observed in patients with functional (idiopathic) anorectal and defecation disorders. Furthermore, alterations in anorectal physiology appear to reflect the changes seen in other non-related bowel disorders. Therefore, consideration of these physiological differences may aid management decisions within the complex patient group.

This article is protected by copyright. All rights reserved. 


\section{References}

1. Whitehead WE, Borrud L, Goode PS, et al. Fecal incontinence in US adults: epidemiology and risk factors. Gastroenterology 2009;137(2):512-7, 17 e1-2.

2. Higgins PD, Johanson JF. Epidemiology of constipation in North America: a systematic review. Am J Gastroenterol 2004;99(4):750-9.

3. Nelson R, Norton N, Cautley E, et al. Community-based prevalence of anal incontinence. JAMA 1995;274(7):559-61.

4. McCrea GL, Miaskowski C, Stotts NA, et al. A review of the literature on gender and age differences in the prevalence and characteristics of constipation in North America. J Pain Symptom Manage 2009;37(4):737-45.

5. Sailer, Bussen, Debus, et al. Quality of life in patients with benign anorectal disorders. British Journal of Surgery 1998;85(12):1716-19.

6. Chatoor DR, Taylor SJ, Cohen CR, et al. Faecal incontinence. Br J Surg 2007;94(2):134-44.

7. Chaliha C, Sultan AH, Bland JM, et al. Anal function: effect of pregnancy and delivery. Am J Obstet Gynecol 2001;185(2):427-32.

8. Hill J, Hosker G, Kiff ES. Pudendal nerve terminal motor latency measurements: what they do and do not tell us. Br J Surg 2002;89(10):1268-9.

9. Munoz-Duyos A, Navarro-Luna A, Brosa M, et al. Clinical and cost effectiveness of sacral nerve stimulation for faecal incontinence. $\mathrm{Br} \mathrm{J}$ Surg 2008;95(8):1037-43.

This article is protected by copyright. All rights reserved. 
10. Diamant NE, Kamm MA, Wald A, et al. AGA technical review on anorectal testing techniques. Gastroenterology 1999;116(3):735-60.

11. Birnbaum EH, Stamm L, Rafferty JF, et al. Pudendal nerve terminal motor latency influences surgical outcome in treatment of rectal prolapse. Dis Colon Rectum 1996;39(11):1215-21.

12. Thiruppathy K, Roy A, Preziosi G, et al. Morphological abnormalities of the recto-anal inhibitory reflex reflects symptom pattern in neurogenic bowel. Dig Dis Sci 2012;57(7):1908-14.

13. Craggs MD, Balasubramaniam AV, Chung EA, et al. Aberrant reflexes and function of the pelvic organs following spinal cord injury in man. Auton Neurosci 2006;126-127:355-70.

14. Thiruppathy K, Bajwa A, Kuan KG, et al. Gut symptoms in diabetics correlate with components of the rectoanal inhibitory reflex, but not with pudendal nerve motor latencies or systemic autonomic neuropathy. $\mathrm{J}$ Dig Dis 2015;16(6):342-9.

15. Heyt GJ, Oh MK, Alemzadeh N, et al. Impaired rectoanal inhibitory response in scleroderma (systemic sclerosis): an association with fecal incontinence. Dig Dis Sci 2004;49(6):1040-5.

16. Agachan F, Chen T, Pfeifer J, et al. A constipation scoring system to simplify evaluation and management of constipated patients. Dis Colon Rectum 1996;39(6):681-5.

17. Marcio J, Jorge N, Wexner SD. Etiology and Management of Fecal Incontinence. Diseases of the Colon \& Rectum 1993;36(1):77-97.

This article is protected by copyright. All rights reserved. 
18. Evans RC, Kamm MA, Hinton JM, et al. The normal range and a simple diagram for recording whole gut transit time. Int J Colorectal Dis 1992;7(1):15-7.

19. Rasmussen OO, Christiansen J, Tetzschner T, et al. Pudendal nerve function in idiopathic fecal incontinence. Dis Colon Rectum 2000;43(5):633-6; discussion 36-7.

20. Jameson JS, Chia YW, Kamm MA, et al. Effect of age, sex and parity on anorectal function. Br J Surg 1994;81(11):1689-92.

21. Zbar AP, Aslam M, Gold DM, et al. Parameters of the rectoanal inhibitory reflex in patients with idiopathic fecal incontinence and chronic constipation. Dis Colon Rectum 1998;41(2):200-8.

22. Valles M, Mearin F. Pathophysiology of bowel dysfunction in patients with motor incomplete spinal cord injury: comparison with patients with motor complete spinal cord injury. Dis Colon Rectum 2009;52(9):158997.

23. Camilleri M. Testing the sensitivity hypothesis in practice: tools and methods, assumptions and pitfalls. Gut 2002;51(Supplement 1):i34-i40.

24. Chan CL, Scott SM, Williams NS, et al. Rectal hypersensitivity worsens stool frequency, urgency, and lifestyle in patients with urge fecal incontinence. Dis Colon Rectum 2005;48(1):134-40.

25. Cheong DM, Vaccaro CA, Salanga VD, et al. Electrodiagnostic evaluation of fecal incontinence. Muscle Nerve 1995;18(6):612-9.

26. Kamm MA, Lennard-Jones JE. Rectal mucosal electrosensory testing-evidence for a rectal sensory neuropathy in idiopathic constipation. Dis Colon Rectum 1990;33(5):419-23.

This article is protected by copyright. All rights reserved. 
27. Burleigh DE. Evidence for a functional cholinergic deficit in human colonic tissue resected for constipation. J Pharm Pharmacol 1988;40(1):55-7.

28. Emmanuel AV, Kamm MA. Laser Doppler flowmetry as a measure of extrinsic colonic innervation in functional bowel disease. Gut 2000;46(2):212-17.

29. Murray CD, Flynn J, Ratcliffe L, et al. Effect of acute physical and psychological stress on gut autonomic innervation in irritable bowel syndrome. Gastroenterology 2004;127(6):1695-703.

30. Emmanuel AV, Kamm MA. Laser Doppler measurement of rectal mucosal blood flow. Gut 1999;45(1):64-69.

31. Roy AJ, Emmanuel AV, Storrie JB, et al. Behavioural treatment (biofeedback) for constipation following hysterectomy. Br J Surg 2000;87(1):100-5.

32. Duthie HL, Bennett RC. The relation of sensation in the anal canal to the functional anal sphincter: a possible factor in anal continence. Gut $1963 ; 4(2): 179-82$.

33. Cheeney G, Nguyen M, Valestin J, et al. Topographic and manometric characterization of the recto-anal inhibitory reflex. Neurogastroenterol Motil 2012;24(3):e147-54.

34. Cook TA, Mortensen NJ. Management of faecal incontinence following obstetric injury. Br J Surg 1998;85(3):293-9.

35. Talley NJ, Weaver AL, Zinsmeister AR, et al. Functional constipation and outlet delay: a population-based study. Gastroenterology 1993;105(3):781-90.

This article is protected by copyright. All rights reserved. 
36. Rothbarth J, Bemelman WA, Meijerink WJ, et al. What is the impact of fecal incontinence on quality of life? Dis Colon Rectum 2001;44(1):6771.

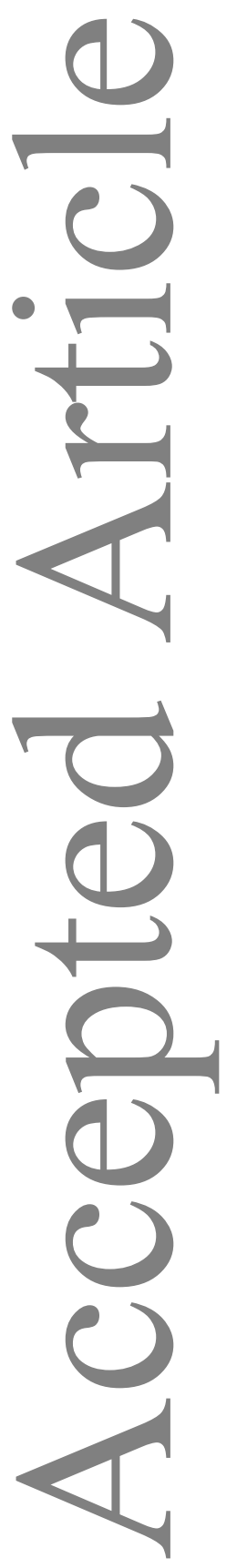

This article is protected by copyright. All rights reserved. 


\section{Figure 1}

The rectoanal inhibitory reflex (RAIR), taken from Thiruppathy et al (2015) ${ }^{12}$ : the point of maximal stimulation is the starting point of the RAIR and the endpoint is when the pressure has recovered to two thirds of the initial resting pressure. The time between these points is the duration of the reflex. Time taken for the pressure to return to resting from maximal amplitude is the excitation latency. Recovery time begins as soon as the RAIR reaches maximal relaxation

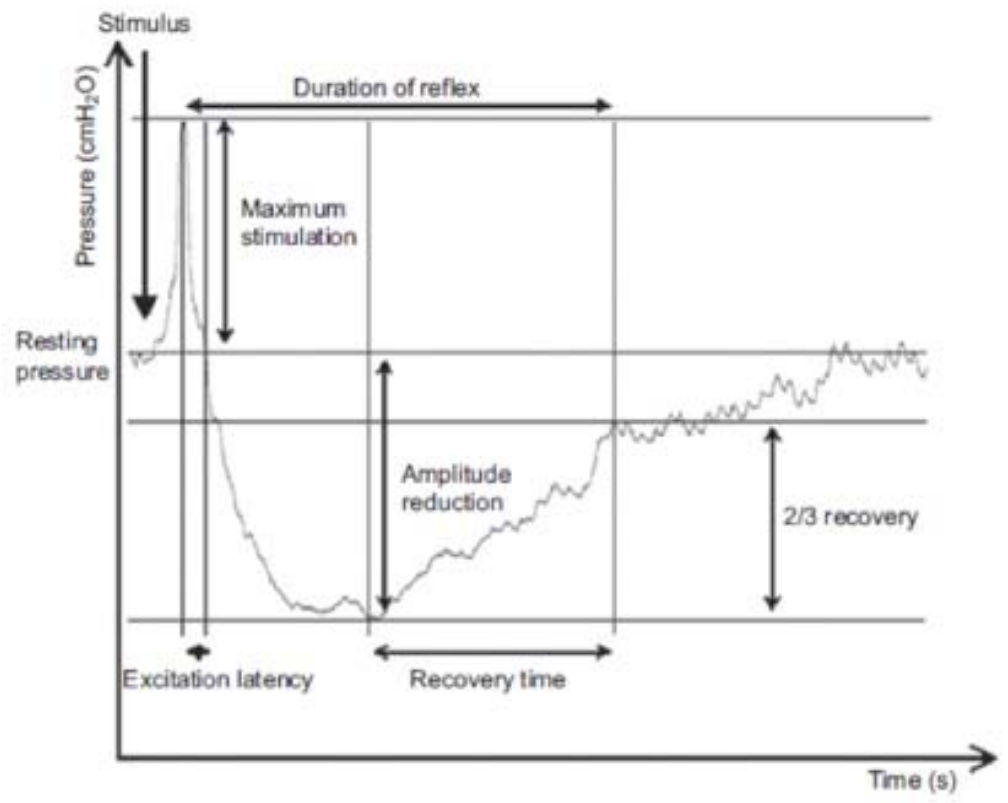

This article is protected by copyright. All rights reserved. 
Table 1

\begin{tabular}{|l|c|c|}
\hline Group & Wexner FI Score (0-24) & $\begin{array}{l}\text { Wexner Constipation } \\
\text { Score (0-30) }\end{array}$ \\
\hline Control & $1.1(0.2)$ & $3.1(1.3)$ \\
\hline Urge FI & $15.4(7.4)$ & $4.1(2.8)$ \\
\hline Passive FI & $18.1(7.5)$ & $4.2(4.3)$ \\
\hline Slow transit & $5.7(3.0)$ & $14.9(8.9)$ \\
\hline Evacuation difficulty & $7.5(2.9)$ & $20.6(12.7)$ \\
\hline
\end{tabular}

Mean (SD) Wexner FI and constipation scores across each of the five study groups. The Wexner FI score ranges from 0-20 with a score of $\geq 9$ shown to correlate with moderate-severe symptoms ${ }^{36}$ and the Wexner constipation score ranges from $0-30$ with a score of $\geq 10$ shown to correlate with moderatesevere symptoms. ${ }^{16}$

This article is protected by copyright. All rights reserved. 
Table 2

\begin{tabular}{|l|c|c|c|c|c|}
\hline Parameter & Controls & Urge FI & Passive FI & $\begin{array}{l}\text { Slow } \\
\text { transit }\end{array}$ & $\begin{array}{l}\text { Evacuation } \\
\text { difficulty }\end{array}$ \\
\hline $\begin{array}{l}\text { Resting } \\
\text { pressure } \\
\left(\mathrm{cmH}_{2} \mathrm{O}\right)\end{array}$ & $87(35)$ & $53(28)^{* \Delta}$ & $38(25)^{\star}$ & $78(21)^{\Delta}$ & $75(28)^{\Delta}$ \\
\hline $\begin{array}{l}\text { Squeeze } \\
\text { pressure } \\
\left(\mathrm{cmH} \mathrm{H}_{2} \mathrm{O}\right)\end{array}$ & $119(52)$ & $37(21)^{\star}$ & $84(38)^{* \dagger}$ & $109(36)^{\dagger \Delta}$ & $102(41)^{\dagger \Delta}$ \\
\hline $\begin{array}{l}\text { Threshold } \\
\text { volume } \\
(\mathrm{mL})\end{array}$ & $34(14)$ & $26(17)$ & $39(18)$ & $49(20)$ & $43(23)$ \\
\hline \begin{tabular}{l}
$\mathrm{DDV}(\mathrm{mL})$ \\
\hline $\mathrm{MTV}(\mathrm{mL})$
\end{tabular} & $166(44)$ & $58(24)$ & $68(34)$ & $94(28)^{\dagger}$ & $90(30)^{\dagger}$ \\
\hline
\end{tabular}

Mean (SD) parameters for anal manometry and rectal sensory function to distention across each study group.

DDV = defecatory urge volume; $\mathrm{MTV}=$ maximum tolerated volume ${ }^{*} p<0.05$ compared to controls; $\uparrow p<0.05$ compared to urge Fl; $\Delta p<0.05$ compared to passive FI

This article is protected by copyright. All rights reserved. 
Table 3

\begin{tabular}{|c|c|c|c|c|c|}
\hline Parameter & Controls & Urge FI & Passive FI & $\begin{array}{l}\text { Slow } \\
\text { transit }\end{array}$ & $\begin{array}{l}\text { Evacuation } \\
\text { difficulty }\end{array}$ \\
\hline $\begin{array}{l}\text { Excitation } \\
\text { latency } \\
\text { (msec) }\end{array}$ & $1.6(0.9)$ & $2.1(0.9)$ & $2.0(0.8)$ & $1.9(1.0)$ & $2.3(0.9)$ \\
\hline $\begin{array}{l}\text { Recovery } \\
\text { time } \\
\text { (msec) }\end{array}$ & $0.5(0.4)$ & $0.8(0.4)$ & $1.2(0.4)^{*}$ & $0.3(0.3)$ & $0.6(0.2)$ \\
\hline $\begin{array}{l}\text { Duration of } \\
\text { reflex } \\
\text { (msec) }\end{array}$ & $4.3(1.7)$ & $4.8(1.9)$ & $6.3(2.1)^{*}$ & $4.2(1.8)$ & $6.6(1.6)$ \\
\hline $\begin{array}{l}\text { RAIR } \\
\text { amplitude } \\
(\%) \\
\text { relaxation }\end{array}$ & 77 (36) & $71(30)$ & $54(33)$ & $64(37)$ & $70(32)$ \\
\hline
\end{tabular}

Mean (SD) parameters of the RAIR.

${ }^{*} p<0.05$ compared to controls

This article is protected by copyright. All rights reserved. 